\title{
Effect of Persian Sage (Salvia rhytidia) Extract on Histomorphometric Changes of Cerebral Cortex and Hippocampus Following Ischemia-Reperfusion Injuries in Rat
}

\author{
Rahil Haghjoo,, ${ }^{1, *}$ and Mina Tadjalli ${ }^{1}$ \\ ${ }^{1}$ Department of Basic Sciences, Faculty of Veterinary Medicine, Shiraz University, Shiraz, IR Iran \\ "Corresponding author: Rahil Haghjoo, Department of Basic Sciences, Faculty of Veterinary Medicine, Shiraz University, Shiraz, IR Iran. E-mail: rahil_haghjoo@yahoo.com
}

Received 2015 February 13; Accepted 2015 August 12.

\begin{abstract}
Background: In the present study the effect of Salvia rhytidia extract on thickness of cerebral cortex and hippocampal regions following ischemia-reperfusion (IR) injuries is evaluated.

Objectives: In the present study the extract of S. rhytidia, an endemic plant from south eastern of Iran, was used to prevent IR injuries induced in cerebral cortex and hippocampus of rats.

Materials and Methods: In this cross-sectional study, 35 male healthy Wistar rats between 250 - $350 \mathrm{~g}$ were randomly divided into 7 groups of 5 rats. Control group (A), ischemic groups (B, D, E, F, G) that left common carotid and left vertebral arteries were occluded for 10 minutes. Group D received S. rhytidia extract $(3.2 \mathrm{mg} / \mathrm{kg})$ and group E received silymarin $(50 \mathrm{mg} / \mathrm{kg})$, a chemical drug which is used for reducing oxidative stress, 2 hours after ischemia, whereas group F received S. rhytidia extract (3.2 $\mathrm{mg} / \mathrm{kg}$ ) and group G received silymarin (50 mg/kg), 72, 48, 24 and o hours before ischemia. Group B received no drug and sham group (C) received normal saline (NS) without ischemia. After 24 hours reperfusion, the brains of rats were prepared for histological studies and the data were analyzed using one way ANOVA and Duncan as posthoc test.

Results: IR resulted in decrease in thickness of the cerebral cortex, CA1 and CA2 regions of the hippocampus in groups B, D and E compared to control $(\mathrm{P}<0.05)$. But no significant decrease observed in thickness of the cerebral cortex and all hippocampal regions in groups $\mathrm{C}, \mathrm{F}, \mathrm{G}$ and $\mathrm{CA} 3$ and dentate gyrus regions of the hippocampus in groups $\mathrm{B}, \mathrm{D}$ and $\mathrm{E}$ compared to control.

Conclusions: This study showed that $S$. rhytidia extract can protect the forebrain from IR injuries due to antioxidative effect of the drug.
\end{abstract}

Keywords: Cerebral Cortex, Hippocampus, Ischemia-Reperfusion, Salvia rhytidia

\section{Background}

Ischemic brain damage is a major cause of adult disability. Forebrain ischemia, occurring during cardiorespiratory arrest in patients or experimentally in animals, induces selective and delayed neuronal cell death [1]. Forebrain ischemia induces complete interruption of blood flow, producing inadequate delivery of oxygen to brain tissue and leading to a decrease in glucose utilization and adenosine triphosphate (ATP). Oxidative stress is one of the primary factors that exacerbate damage by cerebral ischemia [2]. Several components of reactive oxygen species (superoxide, hydroxyl radical, hydrogen peroxide and peroxynitrite radical) that are generated after ischemia-reperfusion (IR) injury play an important role in neuronal loss after cerebral ischemia [3]. Superoxide and hydroxyl radicals are potent in producing destruction of the membrane by inducing lipid peroxidation [4]. The brain is particularly vulnerable to oxidative stress injury because of its high rate of oxidative metabolic activity, in- tense production of reactive oxygen species metabolites and high content of polyunsaturated fatty acids, relatively low antioxidants capacity, low repair mechanism activity and non-replicating nature of its neuronal cells [5]. During IR, tissues are subjected to the destructive proinflammatory cytokines and reactive oxygen species released by inflammatory cells leading to inflammatory injury and cell apoptosis. IR in one organ also affects the secondary organs, including liver, heart [6], kidney [7], lung [8] and even causes multiple organ failure (MOF), a common cause of mortality [9]. The concept of reperfusion injury has been a subject of debate for the past three decades, in which some investigators believe that all injury develops during the ischemic period whereas others argue that blood reflow extends tissue injury due to the release of oxygenderived free radicals, dysregulation of intracellular and mitochondrial calcium, microvascular dysfunction leading to incomplete return of blood flow to areas of microcirculation, an overzealous inflammatory reaction involv- 
ing influx of various populations of immune cells and delayed cell death due to apoptosis [10]. The phenomenon occurs in a wide range of situations including trauma, vascular reflow after contraction, percutaneous transluminal coronary angioplasty, thrombolysis treatment, organ transplantation and hypovolemic shock with resuscitation [11].

Herb medicines had traditionally played a major role in the management of human health and are still playing an active role in the health care in many countries. It has been suggested that for some herbs it is the natural antioxidants they contain conferred their biological activities [12]. Since during the IR injuries, reactive oxygen species (ROS) play the main role, using the herbs with antioxidative properties can be helpful in ameliorating the injuries. Salvia spp. has long used in Asian countries for clinical treatment of various microcirculatory disturbance-related diseases. This herbal drug contains many active watersoluble compounds which have ability to scavenge peroxides and are able to inhibit the expression of adhesion molecules in vascular endothelium and leukocytes [11]. Previous studies about anti-ischemic effects of Salvia miltiorrhiza in brain and liver of rats revealed that it can scavenge the free radicals, also can occlude calcium ion canals in hepatocytes and prevent hepatocytic injuries following ischemia reperfusion injuries $[13,14]$. This plant also scavenges the free radicals producing in mitochondrial membrane of the myocardium following ischemia reperfusion injuries [15].

\section{Objectives}

According to antioxidative effects of different species of salvia genus, we decided to investigate the antioxidaive effect of Salvia rhytidia extract on histomorphometric changes of cerebral cortex and hippocampus following ischemia-reperfusion injuries. In the present study the extract of S. rhytidia, an endemic plant from south eastern of Iran, was used to prevent IR injuries induced in cerebral cortex and hippocampus of rats.

\section{Materials and Methods}

\subsection{Animals}

This cross-sectional study was performed on 35 male Wistar rats between 250 - $300 \mathrm{~g}$. All animals were housed in an air-conditioned room (12 light/dark cycles with a temperature of $21^{\circ} \mathrm{C}$ and relative humidity of $50 \%$ ). The animals were fed commercial rodent pellet food and water. All the procedures were conducted in accordance with the European community guidelines for laboratory animals.

\subsection{Experimental Groups and Surgical Procedures}

Group A: Control; group B: No drug administration, 10 minutes ischemia, 24 hours reperfusion; group C: Manipulation of left common carotid and left vertebral arteries without ischemia, administration of normal saline, sacrificed after 24 hours; group D: 10 minutes ischemia, administration of S. rhytidia 2 hours after ischemia, sacrificed after 24 hours; group E: 10 minutes ischemia, administration of silymarin 2 hours after ischemia, sacrificed after 24 hours; group F: Administration of S. rhytidia, 72, 48, 24, 0 hours before ischemia, 10 minutes ischemia, 24 hours reperfusion; group G: Administration of silymarin, 72, 48, 24,0 hours before ischemia, 10 minutes ischemia, 24 hours reperfusion.

The operation was performed under general anesthesia $[40 \mathrm{mg} / \mathrm{kg}$ ketamine $+4 \mathrm{mg} / \mathrm{kg}$ xylazine intra muscular (i.m.)]. Following surgical preparations, left common carotid and left vertebral arteries were exposed through ventral midline cervical incision, separated from the vagosympathetic trunks and occluded for 10 minutes by Rumel tourniquet at the same time. After 10 minutes both of them were opened and the skin incision was closed with silk sutures, the animals were transferred to their cages.

\subsection{Preparations and Administration of S. rhytidia Extract and Silymarin}

S. rhytidia extract was taken from fresh aerial parts of the plants. The leaves were first made into a crude extract by immersion of the material in an aqueous solvent $(70 \%$ ethanol) at room temperature for a sufficient time, typically 48 hours for all the soluble phytochemicals to dissolve. The solution was then concentrated using a climbing film evaporator or in a finishing still under a vacuum and dried in either a vacuum oven or by lyophilisation (freeze drying). The resulting compound was milled using 44 mesh into a powder resulting in an extract of dried leaf material of S. rhytidia. In group D, S. rhytidia extract $(3.2 \mathrm{mg} / \mathrm{kg})$ and in group E, silymarin $(50 \mathrm{mg} / \mathrm{kg})$ was administered orally 2 hours after operation. In group F the same dose of S. rhytidia and in group G, the same dose of silymarin was administered 72, 48, 24 and 0 hours before operation.

\subsection{Sampling}

At the end of the experiment, rats were deeply anesthetized by diethyl ether, the brains were dissected and cerebrums were removed and left hemispheres were sectioned and inserted in buffer formalin 10\% for 24 hours. 


\subsection{Histological Study for Measuring Thickness of the Cerebral} Cortex and Hippocampal Regions

The formaldehyde-fixed samples were dehydrated, cleared and embedded in paraffin. Sections of $5 \mu \mathrm{m}$ thickness were cut, mounted and stained with hematoxylineeosine method for histological evaluation. The thickness of the cerebral cortex and hippocampal regions was measured using a micrometric lens.

\subsection{Statistical Analysis}

The data were analyzed using SPSS-16, one way ANOVA, and Duncan as post hoc test and the level of significance was considered $\mathrm{P}<0.05$. The data presented in mean \pm SEM.

\section{Results}

4.1. Effect of S. rhytidia Extract on Thickness of the Cerebral Cortex

Results showed that there was a significant decrease in thickness of the cerebral cortex in groups B, D and E compared to group $A(P<0.05)$. In group $F$ which received S. rhytidia extract $(3.2 \mathrm{mg} / \mathrm{kg})$ and group $\mathrm{G}$ that received silymarin $(50 \mathrm{mg} / \mathrm{kg}$ ) before operation the cerebral cortex thickness did not significantly decrease compared to group A. The thickness in group C, partially was similar to group A (Figure 1).

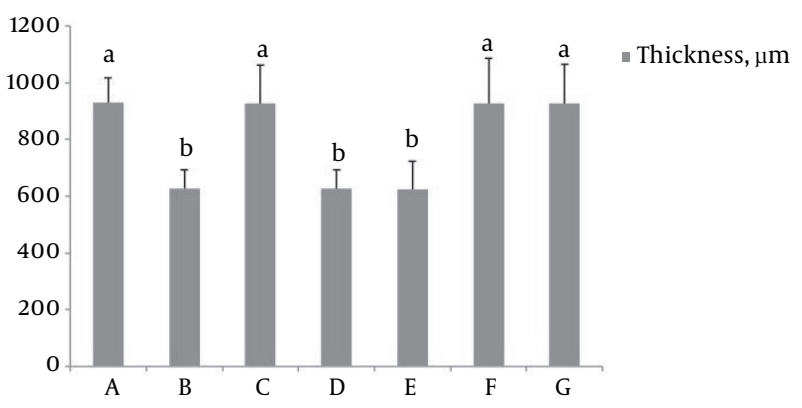

Figure 1. Effect of S. rhytidia Extract on Thickness of the Cerebral Cortex (Mean \pm Standard Error)

4.2. Effect of S. rhytidia Extract on Thickness of Different Zones of the Hippocampus (CA1, CA2, CA3 and Dentate Gyrus)

In groups $\mathrm{B}, \mathrm{D}$ and $\mathrm{E}$, the thickness of the CA1 and CA2 regions decreased compared to group $\mathrm{A}(\mathrm{P}<0.05)$, (Figure $2)$. While the thickness of the all hippocampal regions in groups $F, G$, the $C A 3$ and dentate gyrus regions in groups $B$, $\mathrm{D}$ and $\mathrm{E}$, did not significantly decrease compared to group
A and the results in groups $\mathrm{C}$ and $\mathrm{A}$, partially was similar to each other (Figures 3 - 5).

The different letters represent significant statistical difference between groups $(\mathrm{P}<0.05)$. The results show that the thickness of the polymorphic layer in groups $\mathrm{B}$, D and E significantly decreased compared to control (A), while the thickness of this layer did not significantly decrease in groups C, F and G compared to control.

The different letters represent significant statistical difference between groups $(\mathrm{P}<0.05)$. The results show that the thickness of the pyramidal layer in groups $B, D$ and E, significantly decreased compared to control (A), while the thickness of this layer did not significantly decrease in groups C, F and G compared to control.

The different letters represent significant statistical difference between groups $(\mathrm{P}<0.05)$. The results show that the thickness of the molecular layer in groups B, D and E, significantly decreased compared to control (A), while the thickness of this layer did not significantly decrease in groups C, F and G compared to control.

The different letters represent significant statistical difference between groups $(\mathrm{P}<0.05)$. The results show that the thickness of the polymorphic layer in groups $B$, $D$ and E, significantly decreased compared to control (A), while the thickness of this layer did not significantly decrease in groups C, F and G compared to control.

The different letters represent significant statistical difference between groups $(\mathrm{P}<0.05)$. The results show that the thickness of the pyramidal layer in groups $B, D$ and E, significantly decreased compared to control (A), while the thickness of this layer did not significantly decrease in groups C, F and G compared to control.

The different letters represent significant statistical difference between groups $(\mathrm{P}<0.05)$. The results show that the thickness of the pyramidal layer in groups $B, D$ and E, significantly decreased compared to control (A), while the thickness of this layer did not significantly decrease in groups C, F and G compared to control.

\section{Discussion}

Results of our study revealed that 10 minutes ischemia following by 24 hours reperfusion in forebrain, significantly decreased the thickness of cerebral cortex and all layers of CA1 and CA2 regions of the hippocampus in groups $\mathrm{B}, \mathrm{D}$ and $\mathrm{E}$ compared to group A. While in groups F which received S. rhytidia extract $(3.2 \mathrm{mg} / \mathrm{kg}$ ), and group $\mathrm{G}$ that received silymarin ( $50 \mathrm{mg} / \mathrm{kg}$ ), 0, 24, 48 and 72 hours before ischemia, no statistical decrease observed in the thickness of the cerebral cortex and all regions of the hippocampus compared to control. Our study also demonstrated that ischemia-reperfusion did not significantly ef- 
Figure 2. Effect of S. rhytidia Extract on the Thickness of CA1 Zone of the Hippocampus
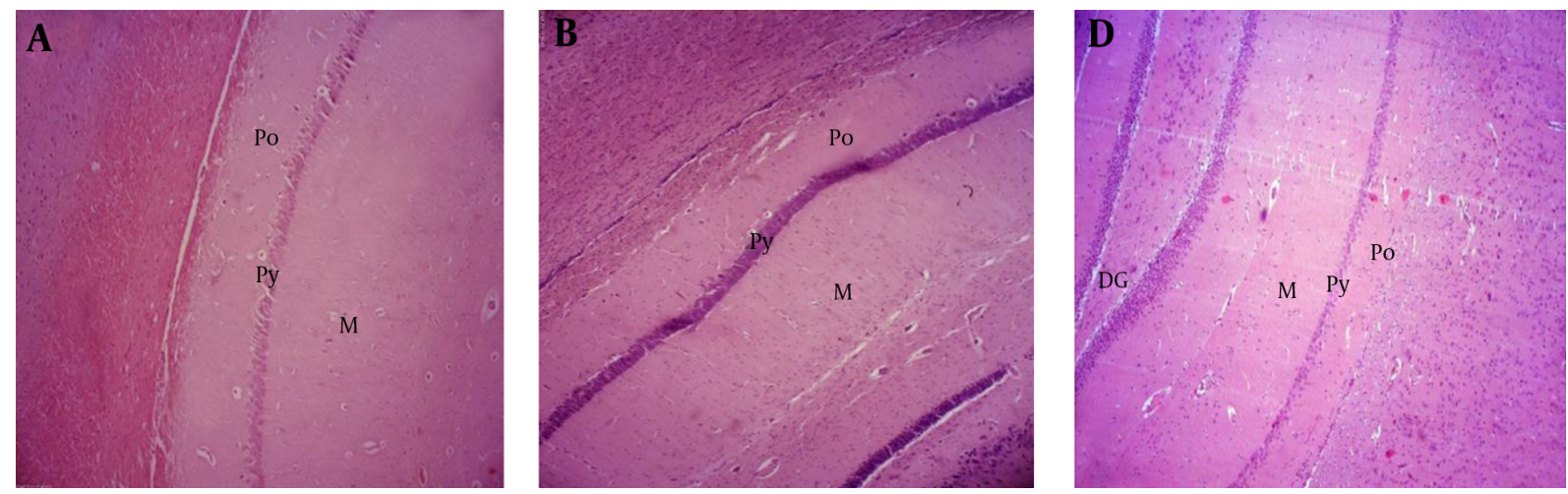

The results show that the thickness of the polymorphic (Po), pyramidal (Py) and molecular (M) layers of the CA1 zone, did not significantly decrease in ischemic groups that received S. rhytidia extract and silymarin 72, 48, 24 and 0 hours before ischemia (B), compared to control (A). The thickness of these layers significantly decreased in ischemic group without receiving drug and in groups that received S. rhytidia extract and silymarin, 2 hours after ischemia (C), compared to control (A).

fect on thickness of the CA3 and dentate gyrus of the hippocampus compared to control.

Cerebral ischemia may be the result of cardiac arrest and/ or secondary focal ischemia following stroke or brain hemorrhage [16-18] Ischemic injury to neurons is primarily due to the interruption of blood flow, lack of oxygenation, drop of ATP and subsequent re-oxygenation of the brain ischemia-reperfusion [19]. Oxidative stress caused by ROS, is known to cause the oxidation of biomolecules leading to cellular damage. Increased lipid peroxidation (LPX) is the major consequence associated with oxidative stress [20].

It has already been a wide range of activities reported for the genus Salvia, which may be relevant for CNS disorders. One of them include antioxidant [21]. The essential oil of the plant, has been tested for its memory enhancing effect [22]. Generally the antioxidant effects of Salvia extracts have often been attributed to phenolic and monoterpenic compounds [23]. Rosmarinic acid is the predominant phenolic compound in Salvia and its effects is attributed to the compound's antioxidant properties acting as scavenger of reactive $\mathrm{O}_{2}$ species [24]. The antioxidant activity of methanolic extracts of Salvia officinalis is comparable to ascorbic acid. Earlier studies attributed the antioxidant activity of S. officinalis to the presence of polyphenolic compounds $[25,26]$. Studies about anti-ischemic effect of aqueous extracts of S. leriifolia leaf and seed in rat hippocampus show that neural cell injury in all regions of the hippocampus was reduced following pretreatment of animals with aqueous seed extract [27]. The results of another investigations indicated that pretreatment with aqueous and alcoholic extracts of S. leriifolia root significantly reduced the elevated concentration of lipid peroxides in rat hippocampus and muscle following ischemia-reperfusion injuries because of its antioxidant properties [27, 28].

Pyramidal neurons in the hippocampal CA1 region are particularly vulnerable to ischemia injury [29].

Results of a study revealed that ischemic injury increased apoptotic neuronal cell death in the hippocampal CA1 region, impaired short-term memory and decreased cGMP level. cGMP plays critical roles in modulating brain functions including neurogenesis and physiological and pathological apoptosis [30]. Another study indicated that increase of potassium was responsible for the decreased excitability in CA1 neurons after severe ischemia and involved in post ischemic cell death in hippocampus [31]. Previous studies also have been shown that neurons in the CA3 and dentate gyrus subfields of the hippocampus are resistant to short period of ischemia which is usually lethal to pyramidal neurons in hippocampal CA1 subfields [32].

Glutamate is the major excitatory transmitter in CNS. Many studies have proved that extracellular glutamate in the brain is accumulated after hypoxia-ischemic insult, which serves as excitotoxin and participates in the induction of delayed neuronal death after brain ischemia [33, 34]. Glial glutamate transporter1 (GLT-1) is a kind of predominant protein which removes glutamates from the extracellular space and maintains the extracellular glutamate below neurotoxic level in the brain [35]. Bruhn et al. observed a progressive post ischemic increase of GLT-1 expression in CA3 after mild brain ischemia for 10 minutes [36]. In animal ischemia-reperfusion model, Salvia prevented myocardial infarction injury, decreased the lipid peroxidation, enhanced antioxidant enzyme activities [12, 37-39] and scavenged free radicals [11, 12, 38, 40, 41].

According to results of this study, it can be concluded that pretreatment with alcoholic extract of S. rhytidia 


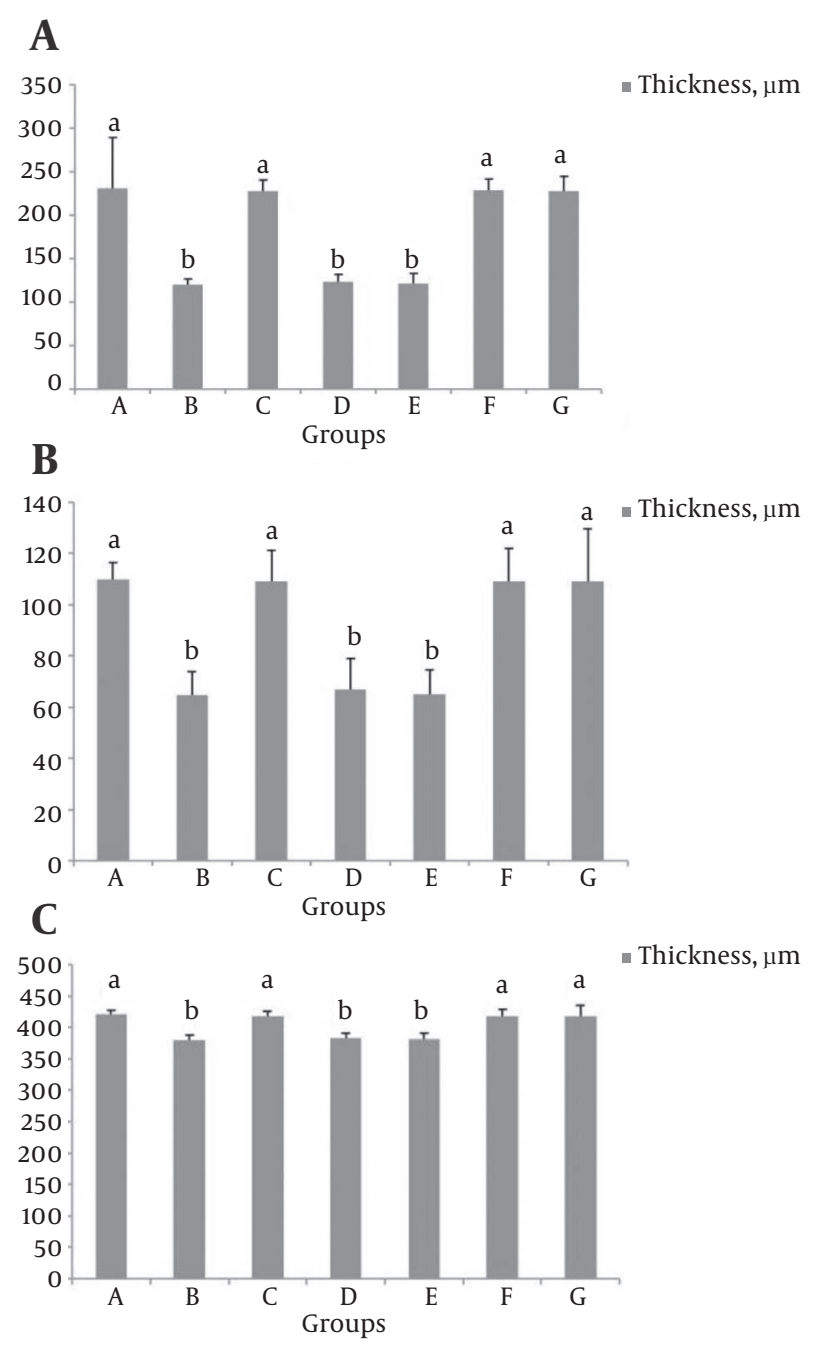

Figure 3. Effect of S. rhytidia extract on thickness of the A, polymorphic layer; B, the pyramidal layer and C, the molecular layer in CA1 zone of the hippocampus (mean \pm standard error).

has potent antioxidant properties similar to silymarin, through which can reverse the IR injuries in the brain of rats.

\section{Acknowledgments}

This article was written based on the PhD thesis approved by School of veterinary medicine, Shiraz university, Shiraz, Iran. The author would like to thank Prof. S. Dehghani from the department of surgery, faculty of veterinary medicine of Shiraz university for performing surgical procedure on rats.
A
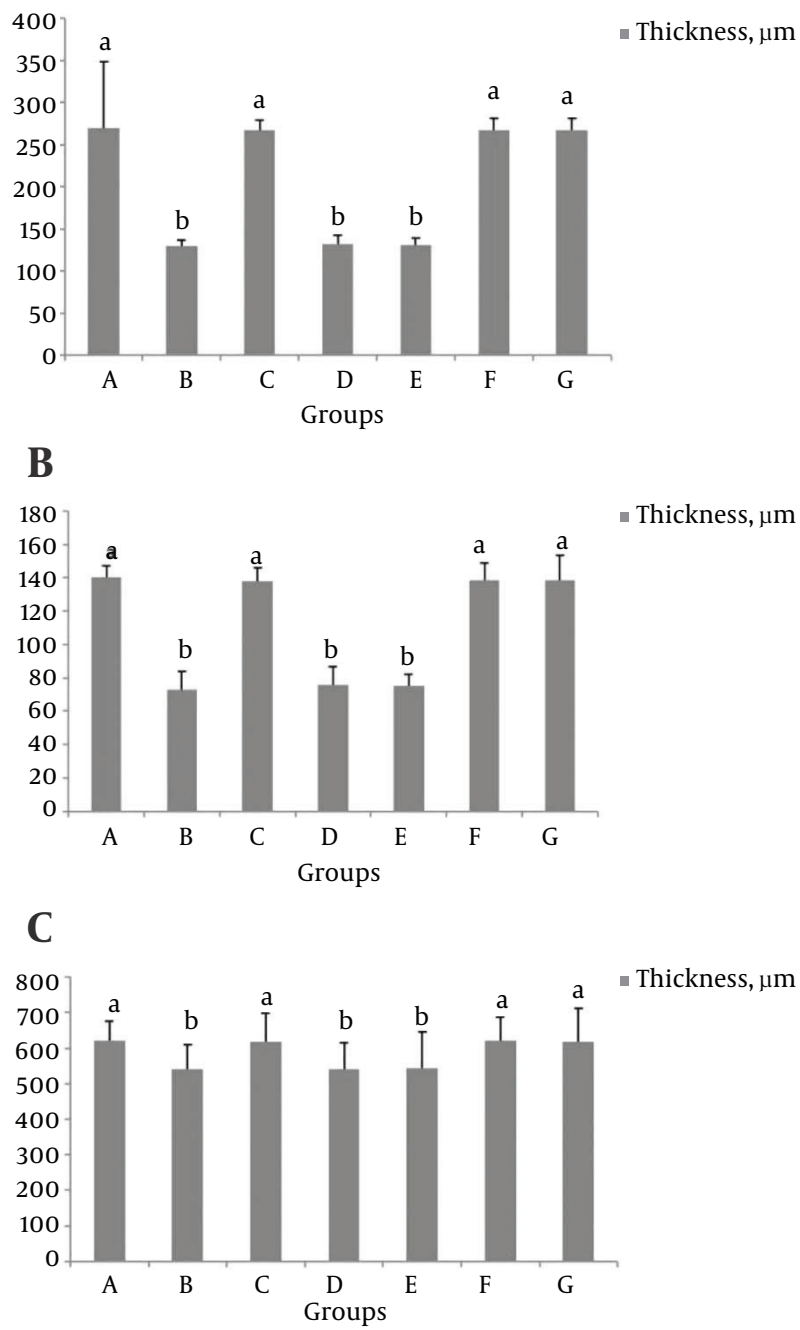

Figure 4. Effect of S. rhytidia extract on thickness of the A, polymorphic layer; B, the pyramidal layer and C, the molecular layer in CA2 zone of the hippocampus (mean \pm Standard error).

\section{Footnotes}

Authors' Contribution: Both authors had equal role in design, work, statistical analysis and manuscript writing.

Funding/Support: Shiraz University, Iran. 
Figure 5. Effect of S. rhytidia Extract on Thickness of Dentate Gyrus Zone of the Hippocampus
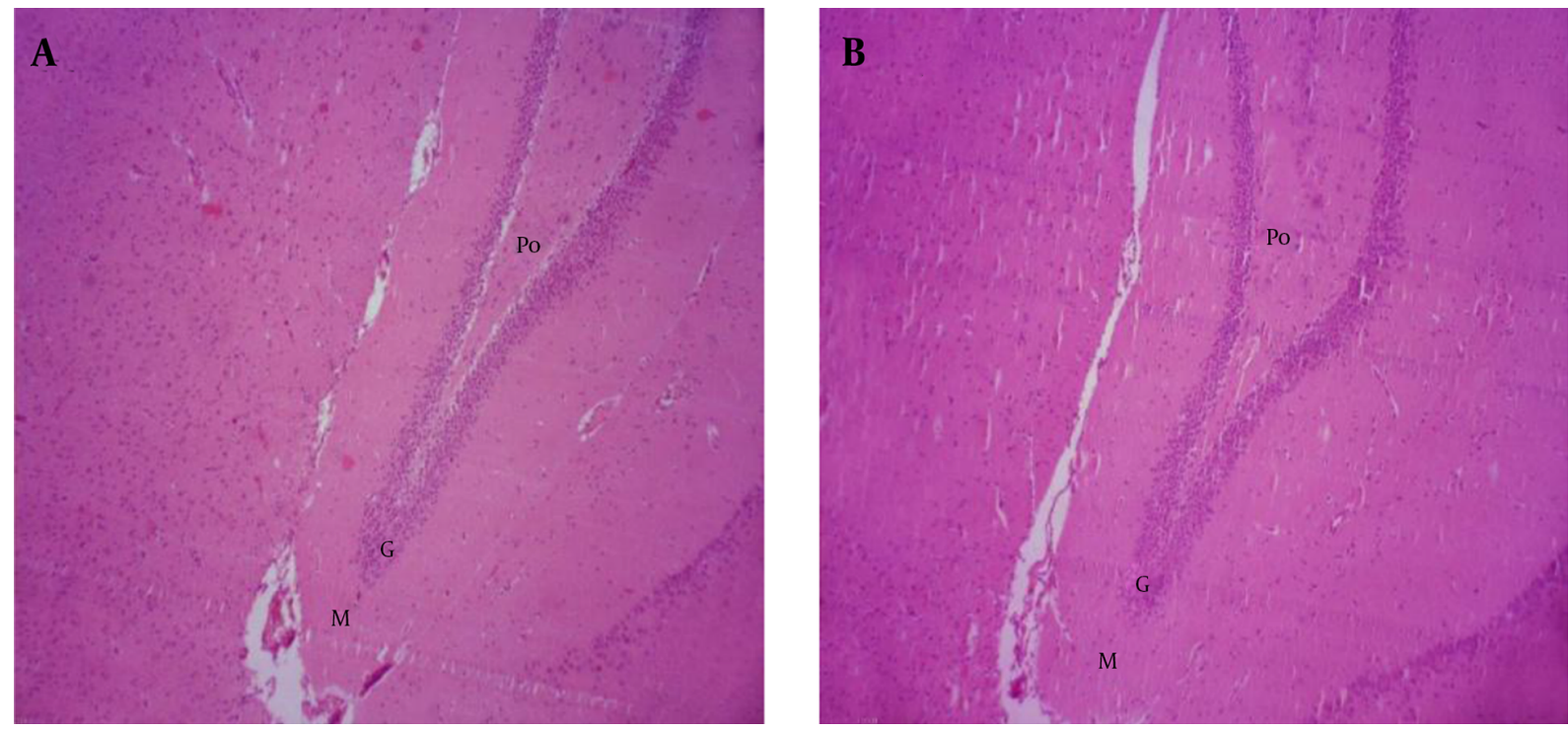

The results show that the thickness of the polymorphic (Po), granular (G) and molecular (Mo) layers of the dentate gyrus, did not significantly decrease in ischemic group without receiving drug and in groups that received S. rhytidia extract and silymarin 2 hours after ischemia (B), compared to control (A).

\section{References}

1. Petito CK, Feldmann E, Pulsinelli WA, Plum F. Delayed hippocampal damage in humans following cardiorespiratory arrest. Neurology. 1987;37(8):1281-6. [PubMed:3614648].

2. Chan PH. Reactive oxygen radicals in signaling and damage in the ischemic brain. J Cereb Blood Flow Metab. 2001;21(1):2-14. doi: 10.1097/00004647-200101000-00002. [PubMed: 11149664].

3. Oliver CN, Starke-Reed PE, Stadtman ER, Liu GJ, Carney JM, Floyd RA. Oxidative damage to brain proteins, loss of glutamine synthetase activity, and production of free radicals during ischemia/reperfusion-induced injury to gerbil brain. Proc Natl Acad Sci U S A. 1990;87(13):5144-7. [PubMed:1973301].

4. Bromont $\mathrm{C}$, Marie $\mathrm{C}$, Bralet J. Increased lipid peroxidation in vulnerable brain regions after transient forebrain ischemia in rats. Stroke. 1989;20(7):918-24. [PubMed: 2749850].

5. Evans PH. Free radicals in brain metabolism and pathology. $\mathrm{Br}$ Med Bull. 1993;49(3):577-87. [PubMed: 8221024].

6. Horton JW, White DJ. Free radical scavengers prevent intestinal ischemia-reperfusion-mediated cardiac dysfunction. J Surg Res. 1993;55(3):282-9. doi: 10.1006/jsre.1993.1141. [PubMed: 8412111].

7. LaNoue JL Jr, Turnage RH, Kadesky KM, Guice KS, Oldham KT, Myers SI The effect of intestinal reperfusion on renal function and perfusion. $J$ Surg Res. 1996;64(1):19-25. [PubMed: 8806468].

8. Savas MC, Ozguner M, Ozguner IF, Delibas N. Splenectomy attenuates intestinal ischemia-reperfusion-induced acute lung injury. J Pediatr Surg. 2003;38(10):1465-70. [PubMed: 14577069].

9. Zhang F, Tong L, Qiao H, Dong X, Qiao G, Jiang H, et al. Taurine attenuates multiple organ injury induced by intestinal ischemia reperfusion in rats. J Surg Res. 2008;149(1):101-9. doi: 10.1016/j.jss.2007.12.781. [PubMed: 18639892].

10. Gross GJ, Auchampach JA. Reperfusion injury: does it exist? J Mol Cell Cardiol. 2007;42(1):12-8. doi: 10.1016/j.yjmcc.2006.09.009. [PubMed: 17069848].

11. Han JY, Fan JY, Horie Y, Miura S, Cui DH, Ishii H, et al. Ameliorating effects of compounds derived from Salvia miltiorrhiza root ex- tract on microcirculatory disturbance and target organ injury by ischemia and reperfusion. Pharmacol Ther. 2008;117(2):280-95. doi: 10.1016/j.pharmthera.2007.09.008. [PubMed: 18048101].

12. Zhao GR, Xiang ZJ, Ye TX, Yuan YJ, Guo ZX. Antioxidant activities of Salvia miltiorrhiza and Panax notoginseng. Food Chem. 2006;99(4):767-74.

13. Lo CJ, Lin JG, Kuo JS, Chiang SY, Chen SC, Liao ET, et al. Ef fect of salvia miltiorrhiza bunge on cerebral infarct in ischemiareperfusion injured rats. Am J Chin Med. 2003;31(2):191-200. doi: 10.1142/S0192415X03000916. [PubMed: 12856858].

14. Lu Q, Shi C, Wu Z. [An experimental and clinical study on radix Salviae miltiorrhiae in the treatment of hepatocellular Ca2+ overload during hepatic ischemia/reperfusion injury]. Zhonghua Wai Ke Za Zhi. 1996;34(2):98-101. [PubMed: 9388333].

15. Zhao BL, Jiang W, Zhao Y, Hou JW, Xin WJ. Scavenging effects of salvia miltiorrhiza on free radicals and its protection for myocardial mitochondrial membranes from ischemia-reperfusion injury. Biochem Mol Biol Int. 1996;38(6):1171-82. [PubMed: 8739039].

16. Sims NR, Anderson MF. Mitochondrial contributions to tissue damage in stroke. Neurochem Int. 2002;40(6):511-26. [PubMed: 11850108].

17. Schurr A. Energy metabolism, stress hormones and neural recovery from cerebral ischemia/hypoxia. Neurochem Int. 2002;41(1):1-8. [PubMed: 11918966].

18. Phillis JW, O'Regan MH. Characterization of modes of release of amino acids in the ischemic/reperfused rat cerebral cortex. Neurochem Int. 2003;43(4-5):461-7. [PubMed: 12742092].

19. Iijima T, Mishima T, Tohyama M, Akagawa K, Iwao Y. Mitochondrial membrane potential and intracellular ATP content after transient experimental ischemia in the cultured hippocampal neuron. Neurochem Int. 2003;43(3):263-9. [PubMed: 12689606].

20. Gray SL, Hanlon JT, Landerman LR, Artz M, Schmader KE, Fillenbaum GG. Is antioxidant use protective of cognitive function in the community-dwelling elderly?. Am J Geriatr Pharmacother. 2003;1(1):310. [PubMed: 15555461]. 
21. Sa CM, Ramos AA, Azevedo MF, Lima CF, Fernandes-Ferreira M, PereiraWilson C. Sage tea drinking improves lipid profile and antioxidant defences in humans. Int J Mol Sci. 2009;10(9):3937-50. doi: 10.3390/ijms10093937. [PubMed: 19865527].

22. Akhondzadeh S, Noroozian M, Mohammadi M, Ohadinia S, Jamshidi $\mathrm{AH}$, Khani M. Salvia officinalis extract in the treatment of patients with mild to moderate Alzheimer's disease: a double blind, randomized and placebo-controlled trial. J Clin Pharm Ther. 2003;28(1):53-9. [PubMed: 12605619].

23. Ren W, Qiao Z, Wang H, Zhu L, Zhang L. Flavonoids: promising anticancer agents. Med Res Rev. 2003;23(4):519-34. doi:10.1002/med.10033. [PubMed: 12710022].

24. Lima CF, Andrade PB, Seabra RM, Fernandes-Ferreira M, PereiraWilson C. The drinking of a Salvia officinalis infusion improves liver antioxidant status in mice and rats. JEthnopharmacol. 2005;97(2):3839. doi:10.1016/j.jep.2004.11.029. [PubMed: 15707779].

25. Bors W, Michel C, Stettmaier K, Lu Y, Foo LY. Antioxidant mechanisms of polyphenolic caffeic acid oligomers, constituents of Salvia officinalis. Biol Res. 2004;37(2):301-11. [PubMed: 15455660].

26. Lu Y, Foo LY. Salvianolic acid L, a potent phenolic antioxidant from Salvia officinalis. Tetrahedron Lett. 2001;42(46):8223-5.

27. Khooei AR, Hosseinzade H, Imanshahidi M. Pathologic evaluation of anti-ischemic effect of Salvia leriifolia Benth seed and leaf extracts in rats after global cerebral ischemia. Iran J Basic Med Sci. 2003;5(4):8-13.

28. Hosseinzadeh H, Hosseini A, Nassiri-Asl M, Sadeghnia HR. Effect of Salvia leriifolia Benth. root extracts on ischemia-reperfusion in rat skeletal muscle. BMC Complement Altern Med. 2007;7:23. doi 10.1186/1472-6882-7-23. [PubMed: 17617916].

29. Sugawara T, Noshita N, Lewen A, Gasche Y, Ferrand-Drake M, Fujimura $\mathrm{M}$, et al. Overexpression of copper/zinc superoxide dismutase in transgenic rats protects vulnerable neurons against ischemic damage by blocking the mitochondrial pathway of caspase activation. Neurosci. 2002;22(1):209-17. [PubMed: 11756504].

30. Ko IG, Shin MS, Kim BK, Kim SE, Sung YH, Kim TS, et al. Tadalafil improves short-term memory by suppressing ischemia-induced apoptosis of hippocampal neuronal cells in gerbils. Pharmacol Biochem Behav. 2009;91(4):629-35. doi: 10.1016/j.pbb.2008.10.009. [PubMed 19010346].

31. Xuan Chi X, Xu ZC. Potassium currents in CA1 neurons of rat hip pocampus increase shortly after transient cerebral ischemia. Neurosci Lett. 2000;281(1):5-8. [PubMed: 10686402].
32. Zhang M, Li WB, Liu YX, Liang CJ, Liu LZ, Cui X, et al. High expression of GLT-1 in hippocampal CA3 and dentate gyrus subfields contributes to their inherent resistance to ischemia in rats. Neurochem Int. 2011;59(7):1019-28. doi: 10.1016/j.neuint.2011.08.023. [PubMed: 21925558].

33. Nicotera P, Bano D. The enemy at the gates. Ca2+ entry through TRPM7 channels and anoxic neuronal death. Cell. 2003;115(7):768-70. [PubMed:14697196].

34. Yeh TH, Hwang HM, Chen JJ, Wu T, Li AH, Wang HL. Glutamate transporter function of rat hippocampal astrocytes is impaired following the global ischemia. Neurobiol Dis. 2005;18(3):476-83. doi: 10.1016/j.nbd.2004.12.011. [PubMed:15755674].

35. Rao VL, Dogan A, Bowen KK, Todd KG, Dempsey RJ. Antisense knockdown of the glial glutamate transporter GLT-1 exacerbates hippocampal neuronal damage following traumatic injury to rat brain. Eur J Neurosci. 2001;13(1):119-28. [PubMed: 11135010].

36. Bruhn T, Levy LM, Nielsen M, Christensen T, Johansen FF, Diemer NH. Ischemia induced changes in expression of the astrocyte glutamate transporter GLT1 in hippocampus of the rat. Neurochem Int. 2000;37(23):277-85. [PubMed: 10812213].

37. Asadi S, Ahmadiani A, Esmaeili MA, Sonboli A, Ansari N, Khodagholi F. In vitro antioxidant activities and an investigation of neuroprotection by six Salvia species from Iran: a comparative study. Food Chem Toxicol. 2010;48(5):1341-9. doi: 10.1016/j.fct.2010.02.035. [PubMed: 20197079].

38. Esmaeili MA, Sonboli A. Antioxidant, free radical scavenging activities of Salvia brachyantha and its protective effect against oxidative cardiac cell injury. Food Chem Toxicol. 2010;48(3):846-53. doi: 10.1016/j.fct.2009.12.020. [PubMed: 20036303].

39. Tepe B, Daferera D, Sokmen A, Sokmen M, Polissiou M. Antimicrobial and antioxidant activities of the essential oil and various extracts of Salvia tomentosa Miller (Lamiaceae). Food chem. 2005;90(3):333-40.

40. Zhao GR, Zhang HM, Ye TX, Xiang ZJ, Yuan YI, Guo ZX, et al. Characterization of the radical scavenging and antioxidant activities of danshensu and salvianolic acid B. Food Chem Toxicol. 2008;46(1):73-81. doi: 10.1016/j.fct.2007.06.034. [PubMed:17719161].

41. Tepe B. Antioxidant potentials and rosmarinic acid levels of the methanolic extracts of Salvia virgata (Jacq), Salvia staminea (Montbret \& Aucher ex Bentham) and Salvia verbenaca (L.) from Turkey. Bioresour Technol. 2008;99(6):1584-8. doi: 10.1016/j.biortech.2007.04.008. [PubMed:17531471]. 